\title{
Construction of Intelligent Science and Technology Major Laboratory Group with Electric Power Characteristics
}

\author{
YiMin $\mathrm{Hou}^{*}$ and XiangMin Lun \\ School of Automation Engineering, Northeast Dianli University, Jilin 132012, China \\ ymh7821@163.com,xm_lun77@163.com
}

Keywords: Laboratory Construction; Intelligent Science and Technology; Electric Characteristics; Practice Ability

\begin{abstract}
In this paper, the construction procedure of Intelligent Science and Technology major laboratory group is introduced. The group is separated into several laboratories and the framework of it is showed by construction figure. After 3 years of work from 2012 to 2015, the construction of the major laboratory group is finished and based on the laboratory group, many achievements have made in the college students education process, and the teaching and research ability of the teachers in this major are improved rapidly.
\end{abstract}

\section{Introduction}

The electric power industry is very meaningful for the Chinese economy, safety, social statistics and improvement of people life the. With the development of science and technology and the innovation of society, the electric enterprises are trying to push on the innovation of the technology and management. The electric system intelligence is one of the major targets of them in the future. The realizing scientific optimization of intelligent of all the procedures between electric generation and consumption has already been a novel trend and a complex science problem for the improvement of global electric system. The development of electric industry intelligent will cause the innovation of electric generation and electric net plan, working, market transactions, and service pattern. It will make the electric system move towards the direction of resource saving, environment friendly and intelligent operation. Therefore, the talents who can combine with the two knowledge frameworks of Intelligent Science and Technology and Electric System Working are urgent needed[1,2].

With the development trend of electric system intelligence, the Northeast Dianli University applied for a new major - Intelligent Science and Technology in 2012. This application was proved in 2013. This major will combine with many advanced technologies, such as Electronic and Circuit, Sensor and Measurement, Computer Hardware and Software, Artificial Intelligence and Intelligent System. It is an interdisciplinary of Control Theory, Detection Technology, Electronic Technology, Computer Technology, Automation Technology, Optical Engineering and Intelligent Theory. On the other side, this major has the obvious electric characteristics.

With the rising demands of college students' practice ability, innovation consciousness and enterprising spirit, the construction of the laboratory with reasonable structure, complete facilities, novel contents and outstanding features becomes one of the research hot spots of the educational administrators[3,4]. As a new major, it should be an important task to build the laboratory.

\section{The Situation of Intelligent Science and Technology Major in the University}

The graduated students of this major in the university should have professional and creative thought of control theory and information theory. They should also have the knowledge and technology of intelligent system and applications, intelligent information processing, electronic technology and software technology comprehensively. More important, the students' knowledge structure should have an obvious characteristic of 
electric power system. They can work in the fields of design and development, engineering application and management in the production of electricity intelligent control, intelligent power grid and metallurgy, chemical industry and other related industrial enterprises intelligent production processes.

At present, although there are more than 20 colleges and universities have this major in the country, only 2 in the northeast part of China[5]. There is no university who has this major in Jilin Province. This major will developt rapidly in the future. There will be a lot of demands for this kind of talents. The university already has this major in 2013 and seized the leading position in the future development of this major. Therefore, the comprehensive construction of Intelligence Science and Technology major in the university has adapted to the social development, especially the development of electric power industry requirements and will make great contribution for Jilin Province in the fields of society and economy.

\section{The Target and Plan of Laboratory Construction}

This major tries to build a professional group of laboratories with advanced equipment and perfect facilities. It can meet the need of Intelligence Science and Technology major students in teaching, course design and student extra-curricular activities of science and technology practice[6-8].

The construction is combined with Electronic Technology Laboratory (for the courses of Circuit Principle, Analog Electronics Technology, Digital Electronics Technology), Signal Processing and Analysis Laboratory (for the courses of Signal and Systems, Modern Digital Signal Processing), the microcomputer Principle and Interface Technology Laboratory (for the course of Microcomputer Principle and Interface Technology), Software Technology Laboratory (for the courses of Software Technology Foundation, Artificial Intelligence), Intelligent Measurement and Control Comprehensive Laboratory (for courses of Intelligent Control, Intelligent Instrument, Intelligent Instrument Design), Robots Comprehensive Laboratory (for the courses of Robots, Robot Route Planning and Control, Intelligent Robot Design), Embedded System Comprehensive Laboratory (for the courses of Modern Digital Signal Processing, Embedded System Principle and Design) and the most important laboratory, Power Plant Procedure ControlLaboratory(for the courses of ThermalPower Plant and Thermal Procedure Process Intelligent Control).

In addition, the laboratory also has a College Students Innovation and Practice Comprehensive Platform. Based on the relevant equipments in every laboratory, the platform can provide the excellent conditions and environment for the students' science and technology practice.

\section{The Content and Results of Laboratory Construction}

The content of laboratory construction. After the planning and construction above, the laboratory of this major works well and the teaching effectiveness is good. The following works have been finished:

1) Construction of laboratory framework

After working for 3 years, the laboratory of Intelligent Science and Technology major are finished. The main contents of the construction are shown in Fig. 1.

2) Experiments content

In the construction of the laboratory structure frame, the experiment contents are also set reasonable as the following aspects.

a) Practical ability cultivation

The experiment content is separated into basic experiments, major comprehensive experiments and innovation experiments. Many of the experiments are set as the innovation experiments. In these experiments working, the students should design the experiments procedure and finish them by themselves.

b) Joint Cultivation of University and Enterprises 
Some cultivations of this major are set as learning and practice procedure in some enterprises. These enterprises working are related with intelligent science and technology. For example, some software technology experiments are finished in software companies.

\begin{tabular}{|c|c|c|}
\hline \multicolumn{3}{|c|}{$\begin{array}{c}\text { College Students Innovation and Practice } \\
\text { Comprehensive Platform }\end{array}$} \\
\hline \multicolumn{3}{|c|}{ Major Comprehensive LBs } \\
\hline $\begin{array}{c}\text { Embedded } \\
\text { system LB }\end{array}$ & $\begin{array}{c}\text { Robot } \\
\text { Comprehensive LB }\end{array}$ & $\begin{array}{c}\text { Power Plant } \\
\text { Procedure Control LB }\end{array}$ \\
\hline \multicolumn{3}{|c|}{ Major Basic LBs } \\
\hline $\begin{array}{c}\text { Microcomputer } \\
\text { Theory LB }\end{array}$ & $\begin{array}{c}\text { Signal } \\
\text { Process LB }\end{array}$ & $\begin{array}{c}\text { Intelligent Measure and } \\
\text { Control LB }\end{array}$ \\
\hline \multicolumn{3}{|c|}{ Public Basic LBs } \\
\hline Electronic & $\begin{array}{c}\text { Automatic } \\
\text { Control LB }\end{array}$ & $\begin{array}{c}\text { Software } \\
\text { Technology LB }\end{array}$ \\
\hline
\end{tabular}

Fig. 1 Construction of Intelligent Science and Technology Major Laboratory

c) Electric power characteristics

The main education and research content of the university is electric power system. Therefore, many experiments and practices procedures are finished in Power Plant.

The results of laboratory construction. After 3 years of work, the running effectiveness of this laboratory is good.

1) The practice ability of the students is improved rapidly. After the training and practice in the laboratories, the students in this major mostly joined in the College Students Innovation and Practice Comprehensive Platform. They can work on some little projects related with intelligent science and technology. More important, the best students in the laboratories will have the opportunities to attend several kinds of science and technology contests which are hold by the government education institutions for the university students.

In recent years, the students have gained more than 40 awards in these contests.

2) The science research ability of the teachers in the major is improved. After 3 years, the research institutions have been constructed in the major. The research directions and contents are related with intelligent science and technology. And some projects proved by government science and technology management institutions are related with electric power closely. For example, a project named "Analysis on Commercial Video Low-level Feature Influences to Viewers' Affective State and Study on Its Multi-channel Information Fusion Technology" was proved by Science and Technology Institution of Jilin Province in 2014. Another project named "Electric Power Robot Vision Recognition System Research Based on SIFT" was proved in 2014. In 3 years, we have got 1 project of National Natural Science Foundation 5 projects of Jilin Province Science and Technology Plan and more than 10 projects of Jilin City Science and Technology Research.

\section{Summary}

In this paper, the construction of Intelligent Science and Technology major laboratory is introduced. To finish the education procedure of this major, a laboratory group with advanced equipment and perfect facilities should be established. After 3 years of work from 2012 to 2015, the construction of the major laboratory group is finished and the framework of this platform is listed in this paper. Based on the laboratory group, many 
achievements have gained in the college student education process has gained, and the teaching and researching ability of the teachers in this major are improved rapidly.

\section{References}

[1] Zhang Xuehong, Wang Ruichun, Dong Dapeng, et al. Power System Development and Implementation Path of Low-carbon Economy in China[J]. Water Resources and Power, 2012, 30(2): 200-203.

[2] Zhu Tingting, Cao Na, Qu Xufeng. The Configuration Method of Clock Synchronization System for Smart Grid[J]. Power System Automation. 2014, 36(6): 89-92.

[3] Zhang Qiong. Discussion on Knowledge Using and Cultivation of Practical Ability[J]. Global Education. 2011, 40(3): 28-33.

[4] Tang Jiale, Cheng Fang, Huang Chunhui, et al. Cultivation of Practice Ability and Innovation Ability of College Students for Quality Education[J]. 2013, 32(1): 88-90.

[5] Yang Peng, Zhang Jianxun, Liu Jiwei, Zhang Lei. A Study on the Course System and Textbook Construction for the Discipline of Intelligence Science and Technology[J]. Computer Education. 2010, 17(19): 11-15.

[6] Cai Zixing. Thinking about Development Strategies of Intelligence Science and Technology Discipline[J]. Computer Education. 2011, 18(15): 9-11.

[7] Zhao Yong, Wang Wenqing. Innovation on Practice Teaching System of Intelligent Science and Technology in LocalEngineering Colleges[J]. Journal of Xi' an Aeronautical University. 2013, 31(5): 71-74.

[8] Liu Changhui, Zhang Yanduo, Wang Haihui, et al. Innovation of Talents Training Mode Intelligent Science and Technology Specialy in Local College[J]. Journal of Wuhan Institute of Shipbuilding Technology. 2013, 10(3): 96-99. 